
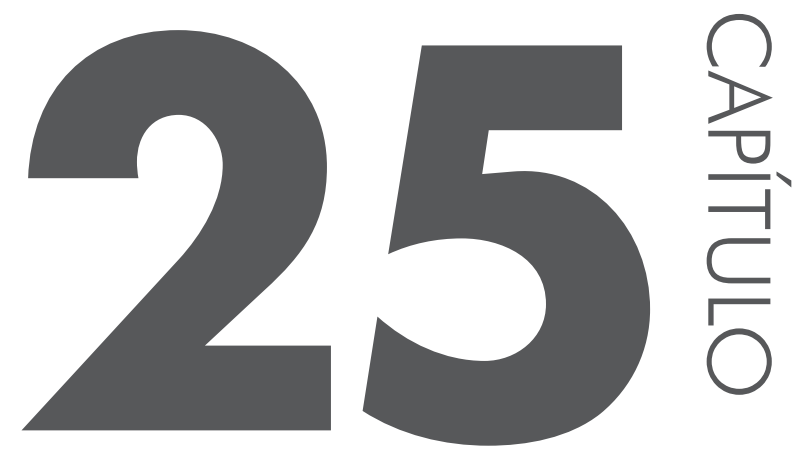

\title{
O cheiro das coisas: mobilidade social e ambientes em fluxo no Atlântico Sul
}

\author{
Jess Auerbach \\ Universidade de Stanford \\ Tradução: Leticia Cesarino (UFSC)
}

Começarei com um mapa que normalmente utilizo quando falo do meu trabalho, pois ele explicita o modo como venho conceitualizando meu campo de pesquisa. Embora a pesquisa seja baseada em Angola, ela exige um engajamento constante com o Atlântico Sul, o que exige repensar espaço e poder nos termos de tradições fora do eixo do chamado norte global. Mesmo Portugal é frequentemente considerado insignificante. Autores como Luis Felipe de Alencastro (que, como muitos outros, publica principalmente em português) documentaram a co-constituição do Brasil por Angola, e de Angola pelo Brasil.

Uma breve digressão histórica dessas relações começaria pelo colonialismo português do século XV, em que a costa de Angola fornecia escravos para o Brasil. Os portugueses só ocuparam o interior quando ficou claro que se eles não o fizessem, alguma outra potência colonizadora o faria; todavia, não fizeram muito por lá. Em 1975, a Revolução dos Cravos em Portugal levou duzentos mil portugueses a deixarem o país no espaço de uma semana, deixando quase tudo para trás. A partir desse momento, dois grupos rivais (MPLA e UNITA) passaram a reivindicar a liderança da nova nação, deslanchando uma guerra civil alimentada pelo contexto da Guerra Fria. A guerra civil só terminou em 2002, com a morte 
de Jonas Savimbi, líder da UNITA. O contexto da reconstrução tem sido marcado pela exploração de enormes reservas de petróleo e diamantes, acompanhada de notável crescimento econômico.

Meu interesse por Angola foi despertado pelo pai do meu melhor amigo na infância, que tinha transtorno de stress pós-traumático (TEPT), e ninguém falava sobre isso. Após ler bastante, comecei a refletir sobre como Angola era sempre vista negativamente, e se seria possível focar naquilo que é positivo. Daí o presente projeto sobre as classes emergentes: pessoas nem no limiar da pobreza, nem parte das elites - o que suscita diversas questões teóricas importantes que não vou explorar aqui. O trabalho de Mark Leichty chama atenção para as "condições de possibilidade" para a emergência das classes médias, e ao trabalhar entre os contextos angolano e brasileiro, foquei nessas condições. Não esperava, contudo, que a questão dos odores surgisse como algo extremamente relevante.

Teorias tradicionais sobre mobilidade social, quando aplicadas a Angola, normalmente assumem a forma "sim, mas...". Na minha tese, eu as discuto mais a fundo. Aqui, quero destacar a noção de interjacência de Mark Leichty, que se baseia em Edward Soja, geógrafo cultural:

\begin{abstract}
A interjacência aponta para as implicações de como grupos sociais (classes, grupos étnicos ou raciais, de gênero) se organizam no espaço, e em particular como a organização espacial manifesta e reproduz relações de poder. Ao invés de serem simplesmente adjacentes, a ideia de interjacência enfatiza o fato de que grupos sociais - fisicamente misturados ou segregados - nunca são ontologicamente independentes uns dos outros, mas são sempre inter-efetivos, interprodutivos e mutuamente constitutivos”. (LIECHTY, 2003, p. 276).
\end{abstract}

A noção de interjacência sugere um modo diferente de pensar tanto a "classe média angolana" enquanto inerentemente local e global, como Angola enquanto país que, ao menos na costa, tem sido constantemente atraído ante o Atlântico e a África - a ponto de, quando o Brasil declarou sua independência, em 1822, um grupo em Benguela ter feito a mesma coisa. O modo como interjacência é definida também é útil para compreender os cheiros, que são conhecidos e identificáveis apenas no diálogo olfativo com outros odores reconhecíveis (por exemplo, você cheira o café no dia do bagel e chora por dentro antes de beber, pois sabe como é o cheiro de um café realmente bom). Isso leva à proposta de se pensar osmologia enquanto cosmologia.

A osmologia é a ciência dos odores, cosmologia, o conhecimento sobre o mundo: durante meu trabalho de campo, percebi, para minha surpresa, que a osmologia era um ponto de entrada importante para conhecer melhor meu objeto. No campo, tomei consciência do perfume através do olfato incrivelmente astuto 
da minha amiga Vitória, que era capaz de identificar os perfumes nos corpos das pessoas na rua: “ah este é o Tommy Hilfiger 'Freedom', aquele o Britney Spears 'Radiance', aquele é d'O Boticário" etc. Ou, franzindo o nariz, “esse é barato, deve vir da China!”. A sensibilidade de Vitória me ajudou a prestar mais atenção nos odores e no modo como, no clima subtropical quente de Angola, os odores tendem a persistir nos corpos, marcando suas trajetórias através do espaço. Quando comecei a ensinar música numa escola fundamental privada, diversas mulheres vieram a mim sugerir que, diante do meu novo papel enquanto figura pública, eu deveria investir num bom perfume. Vitória me ajudou a gastar os U\$150 necessários para comprar um Nina de Nina Rici.

Eu não estava preparada para lidar com perfumes, e ainda estou explorando a literatura teórica sobre o tema. É uma substância interessante porque se situa na fronteira do corpo: remete ao mundo íntimo, sobre a pele é transformado pela química do corpo e por ela singularizado. Ao mesmo tempo, é algo externo, ligado a regimes estéticos e de consumo intimamente ligados à produção e marketing. O perfume contribui assim para uma legibilidade geográfica nos odores manifestos - basta pensar na primeira respiração quando se chega num novo país, ou no cheiro bem básico de um determinado lugar.

Muitas pessoas falaram comigo sobre perfumes, e minha etnografia levou a quatro pontos simples: i) o tipo de perfume utilizado demarca sua conexão com o mundo, seja com o sul ou norte globais, assim como com sua relação com o mundo do trabalho; ii) a "vaidade" que caracteriza os angolanos é produto tanto da estética lusófona quanto da especificidade de reivindicações identitárias no pós-guerra; iii) o duty free é um espaço extremamente significativo para a produção da distinção da classe média angolana; iv) e finalmente, o odor é parte sutil, porém importante da construção e delimitação comunitárias, e não saber lidar com ele pode ter consequências para a mobilidade social.

Tomemos os perfumes de Daniela. Quando a conheci, era uma professora universitária que havia estudado no Brasil e retornou a Angola para dar aulas numa universidade pública local, além de ter outros negócios paralelos. Numa noite em que estava em sua casa, pedi que ela me contasse sobre a caixa de perfumes que mantinha no seu quarto. Ela disse:

Lembro de todos eles. Passei por uma fase onde eu colocava um rótulo no fundo de cada um com sua estória, mas a maioria já caiu. Eu sempre deixo um pouco no fundo pra que possa continuar cheirando, e o cheiro me faz lembrar. Por exemplo, este eu usava quando comecei a trabalhar na katyavala bwila. Este foi presente do primeiro namorado, e este eu usei quando fui pro Brasil, é d'O Boticário. Este eu usava quando fazia estágio no Brasil tentando ganhar dinheiro. Eu não tinha dinheiro, então ele é bem barato. E aqui é o mais caro, da Coco Chanel. Naquela época eu era muito rica e pensei: vou comprar isso. Este eu usava quando tive meus primeiros clientes 
nos negócios, alguns chineses. E este estou usando agora, mas já acabou, tenho que comprar mais. Sim, eu uso todo dia, mas só pela manhã, uma vez ao dia.

Daniela era modesta e trabalhadora. Para ela, perfume mais de uma vez ao dia era exagero. Mas um amigo em comum tinha outra versão; Celestino, que morava no Rio de Janeiro, mas era da capital angolana, me contou:

Os homens angolanos são muito vaidosos, mas no bom sentido, de apreciar boas roupas. E perfume é primordial em Angola. Consumimos tanto lá! Nós nos autoafirmamos através do cheiro. Tenho um amigo que consome uma garrafa em vinte dias; ele usa tão rápido porque quer ser a todo momento o homem mais cheiroso do pedaço. No Brasil não é assim. Talvez um ou outro, mas é raro encontrar um homem brasileiro que cuide de si. Os brasileiros são muito mais simples.

De fato, os angolanos - certamente no mundo lusófono, mas também na África do Sul e outros lugares com grandes comunidades de angolanos - são conhecidos pela sua vaidade e pelo modo "exagerado" de se vestirem. Mas, como sugere Celestino, vaidade não é algo a ser julgado, mas uma prática que tem tudo a ver com não ser visto como vítima de sofrimento. Outro rapaz me explicou da seguinte forma:

Perfume é importante não apenas em Angola. Se você cheira bem, chama atenção e dá às pessoas uma boa impressão. Acho que angolanos em geral gostam disso, dessa sensação boa. Outras coisas você pode mostrar. Eu uso um relógio por exemplo [que parece caro, com pulseira de couro] e perfume, mas não corrente ou pulseiras. Mas é porque ainda sou estudante. Eu uso Christian Dior Intense. O cheiro é muito importante para dançar, para momentos íntimos. Nesses momentos é muito importante não cheirar mal. Angolanos são muito mais formais. Você não está mal vestida, mas uma mulher angolana não se vestiria assim. Você também pode deixar passar porque é branca, e brancos geralmente se vestem mal.

O ponto de Xavier é profundo, ainda que talvez incômodo: branquitude traz presunção de privilégio, negritude, de privação ou ameaça. Isso é algo com que os angolanos que viajam através do mundo lusófono, e além, têm tido que lidar por séculos. No Brasil, por exemplo, "parecer angolano” pode significar a diferença entre ser parado pela polícia ou não - e parecer angolano significa parecer rico.

Há vários níveis aqui, nos quais não poderei entrar. Mas quando malhava no Rio, durante minhas tentativas de explorar mais a fundo o mundo da estética, conheci Flávia, que eu soube ser angolana só de olhar (e creio, cheirar): bolsa, vestido, unhas, cabelo. Tornamo-nos boas amigas - ela era médica fazendo especialização em ginecologia - e basicamente me assumiu enquanto um projeto estético. Diz ela: 


\begin{abstract}
Adoro perfume. Os que mais gosto talvez sejam os cinco que uso hoje: Nina Ricci, Carolina Herera, Fantasty by Britney Spears, na faixa mais barata, Paco Rabanne, e Del Pozo, Jesus's In Black, que é masculino, mas eu gosto, e o mais barato, chamado Midnight, também um Calvin Klein. E tenho algo daquela outra linha da Britney. É mais que cinco, mas tudo bem. Gosto também de água de colônia e hidratante. E uso Victoria's Secret às vezes, quando preciso de algo mais barato compro no Duty Free ou peço a alguém para trazer. A maioria dos bons perfumes vem da Europa, embora os EUA também tenha coisas boas. Em todos os momentos do dia tenho um cheiro. Uso os mais baratos para dormir, banho, academia. Tenho perfumes para o trabalho. Os mais caros eu guardo é claro para sair à noite.
\end{abstract}

Naquele ponto, perguntei se ela consideraria namorar um brasileiro. Ela me olhou horrorizada e disse: "está louca, o cheiro deles é horroroso!".

A explicação de Flávia aponta para duas coisas: como o perfume pode ser significativo, e a importância do duty free como ponto de conexão com o exterior. Isso tem a ver com o isolamento de Angola durante a guerra, bem como a falta de produção local. A maioria não tinha nada, mas aqueles que tinham possuíam coisas de muito boa qualidade. Quero chamar atenção para o duty free enquanto um espaço de passagem muito peculiar - passar por ele significa que se é corporalmente membro de uma comunidade global; usar um perfume comprado nele significa ser parte dessa comunidade através de conexões pessoais, familiares ou sociais.

Para finalizar, quero falar sobre o que acontece quando não se navega corretamente nesse universo. Como deve ter ficado claro, durante meu trabalho de campo, o cheiro era uma forma de avaliação do status das pessoas. Mas muitos não podiam arcar com um perfume francês e não tinha acesso ao Duty Free. Perguntei a Vitória quais seriam as consequências de usar um perfume barato - na faixa de preço de U\$ 2-10 no mercado informal - e ela disse que seria terrível, a pessoa poderia se tornar alvo de fofoca.

Lembrei disso quando conheci Anibal, que estudava direito numa grande universidade de Luanda e estava à procura de emprego. Dentro de minutos, eu soube que ele não arranjaria um emprego tão cedo, pois por detrás da fina camada de perfume barato que cercava seu corpo exalava o odor azedo de suor. Um cheiro desse tipo é conhecido em Angola como “catinga”, e é um tema delicado porque afeta muitas pessoas. Pensando sobre o encontro com Anibal ao analisar minhas notas de campo, resolvi mandar um e-mail para Vitória perguntando por que ninguém o havia avisado sobre a sua catinga:

Há duas razões. Primeiro, tem que ser um amigo muito próximo para poder avisar que alguém fede, pois as pessoas se ofendem. Mesmo familiares podem não falar; aprendemos aqui a ser muito cuidadosos com as palavras. Às vezes preferimos fazer 
comentários pelas costas do que falar a verdade na cara. E a outra razão é que ele pode não cuidar de si. Talvez alguém já tenha avisado, mas ele não sabe como resolver o problema. Por exemplo, às vezes as pessoas aqui dizem que quando você cheira muito nas axilas você deve lavá-as com urina e esfregar bastante. Talvez ele não tenha os hábitos ou recursos pra comprar o que precisa para se manter limpo; como você mesma disse, ele estava desempregado [e portanto sem salário]. Tudo remete ao cuidado e higiene pessoal, que é algo muito importante em Angola.

Terminarei por aqui salientando as noções de autocuidado e higiene, porque ilustram bem a importância da osmologia para a cosmologia: se você não sabe como cheirar bem, não te abrem as portas. A atenção aos códigos olfativos tanto em Angola como em outros lugares abre um leque de possibilidades de investigação. Os odores são moldados pelo consumo e socialidade humanos básicos, desde alimentos até sabões, desodorantes, interações com ar condicionado, diferentes tipos de suor. Na mistura entre fluidos corporais e substâncias cosméticas e ambientais, sinais sutis, porém significativos, de pertencimento social e geográfico formam o que Tim Ingold chamaria de traços legíveis - que muitas vezes, devido precisamente a sua química complexa, são considerados um marcador do status pessoal mais autêntico do que a visão ou a audição. Uma vez que tato e paladar são frequentemente interditados socialmente, cheirar uns aos outros talvez seja a forma mais íntima de conhecimento possível.

\section{Referências}

INGOLD, T. The perception of the environment: essays on livelihood, dwelling and skill. London: Routledge, 2002.

LIECHTY, M. Suitably modern: making middle-class culture in a new consumer society. Princeton and Oxford: Princeton University Press, 2003. 